\title{
Trap Response and Fruit Damage by Obliquebanded Leafroller (Lepidoptera: Tortricidae) in Pheromone-Treated Apple Orchards in New York
}

\author{
ARTHUR M. AGNELLO, W. HARVEY REISSIG, STEVE M. SPANGLER, \\ RALPH E. CHARLTON, ${ }^{2}$ AND DAVID P. KAIN \\ Department of Entomology, Cornell University, New York State Agricultural Experiment Station, \\ Geneva, NY 14456
}

\begin{abstract}
Environ. Entomol. 25(2): 268-282 (1996)
ABSTRACT Pheromone disruptants were tested from 1989 to 1992 in western New York to determine effect on trap catch and potential use in the control of obliquebanded leafroller, Charistoneura rosaceana (Harris), using polyethylene tube tie and controlled-release membrane dispensers in plots of $0.2-2.4$ ha. Effectiveness of pheromone at different application rates and canopy locations was evaluated using synthetic pheromone-baited traps, molassesbaited traps, and by inspecting foliar terminals and fruit for leafroller damage. All pheromone treatments significantly reduced (by 56-97\%) pheromone trap catches of male moths compared with catches in nontreated blocks. One application of a natural-blend formulation at 988 dispensers per hectare was better than 494/ha at disrupting trap catch of both flights that accur during the year. However, mated female moths were present in the orchard center as frequently as anywhere else in a pheromone-treated block, indicating either immigration from outside sources or resident females that were not prevented from mating by the pheromone. The membrane dispenser emitted the 3-component natural blend at proportions similar to those in wild female moths. Pheromone traps placed in the tops of trees in a pheromonetreated orchard always caught higher numbers of male moths than those in lower- or middlecanopy positions. Pheromone treatment resulted in fruit damage similar to that of a pheromone + insecticide treatment under low to moderate leafroller population pressure (i.e., 3$5 \%$ fruit damage in untreated orchards); however, no control method was able to reduce damage to acceptable levels in all cases.
\end{abstract}

KEY WORDS Choristoneura rosaceana, mating disruption, apple, bait traps, canopy height, fruit damage

THE OBLIQUEBANDED LEAFROLLER, Choristoneura rosaceana (Harris), which is widely distributed in temperate North America, has become the most serious pest directly damaging fruit in New York apple orchards since it became resistant to the commonly used organophosphate insecticides in the 1970s (Reissig 1978, Reissig et al. 1986). This leafroller overwinters as a 2nd- or 3rd-stage larva on the tree within a hibernaculum, becoming active in the spring when buds begin to open. Spring-generation larvae may eat away large portions of developing fruit. If the fruit survive, they are misshapen with large, deep cavities of healedover injuries. Fruit damaged by these larvae generally fall off the tree. Spring-generation moths emerge in early June, and summer-generation larvae complete their development in late July or early August, after initially feeding on leaf terminals

\footnotetext{
'Department of Entomology, 501 Agricultural Sciences Building, Pennsylvania State University, University Park, PA 16802.

Department of Entomology, 123 Waters Hall, Kansas State University, Manhattan, KS 66506 .
}

and later moving to the fruit. Feeding areas on the fruit are shallow, irregular, and may range from small punctures to large excavations. This injury is more serious than that caused by the spring generation because most injured fruit remain on the tree. Summer-generation moths begin flying in early August. Their larvae feed primarily on foliage but may cause surface injury to fruit if they are abundant. After feeding briefly, 2nd-generation larvae enter their winter hibernacula.

Growers began experiencing increased difficulty controlling $C$. rosaceana with the recommended pesticides during the last several years and, despite multiple insecticide applications, problem orchards usually end up with 3-4\% damaged fruit at harvest (Reissig and Afgnello 1991). The growing resistance of this pest to diverse classes of the currently available insecticides has resulted in imprudent or at times extreme pesticide use patterns as growers attempt to find an application schedule or product mixture that will provide satisfactory control.

Pheromone mating dismuption as a method of controlling tortricid pests has been examined by 
Tuble 1. Orchurd plot details and pheromone treatments applied in obliquebanded leafroller trials, $1989-1992$

\begin{tabular}{|c|c|c|c|c|c|c|}
\hline lear & Orchard & $\begin{array}{c}\text { Tree height, } \\
\text { m }\end{array}$ & Tree spacing, $\mathrm{ml}$ & Plot size, ha & Dispensers/ha & $\begin{array}{l}\text { Dispenser type, } \\
\text { pheromone blend }\end{array}$ \\
\hline \multirow[t]{12}{*}{1989} & \multirow[t]{3}{*}{ Church North } & \multirow[t]{3}{*}{5.5} & \multirow[t]{3}{*}{11.0 by 11.0} & 1.0 & 988 & Tie, natural \\
\hline & & & & 0.8 & 988 & Tie, generic \\
\hline & & & & 0.7 & 1,976 & Tie, generic \\
\hline & Church South & 2.5 & 3.5 by 6.7 & 0.2 & 988 & Membrane, natural \\
\hline & \multirow[t]{3}{*}{ Richardson } & \multirow[t]{3}{*}{6.0} & \multirow{3}{*}{12.2 by 12.2} & 0.7 & 494 & Tie, generic \\
\hline & & & & 0.7 & 988 & Tie, generic \\
\hline & & & & 0.7 & 1,976 & Tie, generic \\
\hline & \multirow[t]{4}{*}{ Shepherd } & \multirow[t]{4}{*}{2.5} & \multirow[t]{4}{*}{6.0 by 7.5} & 0.8 & 494 & Tie, generic \\
\hline & & & & 0.8 & 988 & Tie, generic \\
\hline & & & & 0.8 & 1,976 & Tie, generic \\
\hline & & & & 0.2 & 988 & Membrane, natural \\
\hline & Sodus & 3.0 & 4.5 by 6.0 & 0.2 & 988 & Membrane, natural \\
\hline \multirow[t]{4}{*}{1990} & Eagle Harbor & 3.0 & 3.7 by 5.5 & 2.1 & 988 & Tie, natural \\
\hline & Kuckville & 4.0 & 4.6 by 7.9 & 2.4 & 988 & Tie, natural \\
\hline & Lyndonville' & 2.0 & 1.8 by 3.7 & 1.5 & 988 & Tie, natural \\
\hline & West Somerset & 4.0 & 4.3 by 7.3 & 1.9 & 988 & Tie, natural \\
\hline \multirow[t]{4}{*}{1991} & Eagle Harbor & 3.0 & 3.7 by 5.5 & 2.]. & 988 & Membrane, natural \\
\hline & Lyndonville & 2.0 & 1.8 by 3.7 & 1.5 & 988 & Tie, natural \\
\hline & North Rose & 5.5 & 6.7 by 9.1 & I. 1 & 988 & Mernbrane, natural \\
\hline & West Somerset & 4.0 & 4.3 by 7.3 & 1.9 & 988 & Tie, nitural \\
\hline \multirow[t]{5}{*}{1992} & \multirow[t]{2}{*}{ Eagle: Harbor } & \multirow[t]{2}{*}{3.0} & \multirow[t]{2}{*}{3.7 by 5.5} & 0.6 & 494 & Membrane, natural \\
\hline & & & & 0.6 & 988 & Membrane, natural \\
\hline & \multirow[t]{2}{*}{ Kuckville } & \multirow[t]{2}{*}{4.0} & \multirow[t]{2}{*}{4.6 by 7.9} & 0.6 & 494 & Membrane, natural \\
\hline & & & & 0.6 & 988 & Membrane, natural \\
\hline & West Somersest & 4.0 & 4.3 by 7.3 & 0.6 & 988 & Membrane, natural \\
\hline
\end{tabular}

"Natural blend, 90:5:5\% Z:E11-14:OAc : Z11-14:OH; generic blend, 93:5:2\% Z:E11-14:OAc: inert carrier.

Rothschild (1975), Palaniswamy et al. (1982), Vickers et al. (1985), Charmillot and Vickers (1991), Pfeiffer et al. (1993), Deland et al. (1994), Karg et al. (1994), and Pree et al. (1994). C. rosaceana uses (Z)-11-tetradecen-1-yl acetate (Z11-1.4:OAc) as a primary pheromone component, together with $2 \%$ (E)-11-tetradecen-1-yl acetate (E11-14:OAC) and $\approx 5 \%(Z)$-11-tetradecen-1-ol (Z1.1-14:OH) (Roelofs and Tette 1970, Hill and Roelofs 1979). In previous trials, Weires et al. (1978) obtained an $84 \%$ pheromone trap catch reduction for this species in 0.75 -ha apple orchards treated with aerially applied hollow fibers containing a $50: 50$ blend of $\mathrm{Z}: \mathrm{E} 11-14: \mathrm{OAc}$ (1976) and a blend containing $25 \%$ each of Z,E11-14:OAc and Z,E11-14:OH (1977). In other tests where the pheromones were handapplied, a release rate of $5 \mathrm{mg} / \mathrm{h} / \mathrm{ha}$ of $\mathrm{Z11-14:OAc}$ was ineffective at disrupting the orientation of $C$. rosaceana in plots ( 25 by $30 \mathrm{~m}$ ), and required addition of the other components of the natural blend, F11-14:OAc and Z11-14:OH, to obtain significant reductions in trap capture (Reissig et al. 1978, Roelofs and Novak 1981). Deland et al. (1994) observed an 88-96\% decrease in trap capture using high rates of a 93:7\% Z:E11-14:OAc blend in 0.09-ha plots. Most previous mating disruption studies indicate that disruptants incorporating the complete blend of pheromone components provide better disruption than partial blends, and do so at lower application rates (Cardé and Minks 1995).

To adequately assess the possibility of using mating disruption as a control tactic for this pest, it is desirable to determine the ability of the pheromone to protect the fruit from feeding damage in treated areas that are as large as possible, both to disrupt mate-finding communication among resident moths and to overcome the incidence of mated moths immigrating into pheromone-permeated plots from surrounding habitats. If mated moths are found to be present in pheromone-treated areas, it is valuable to know if the pheromone blend used in disnuptant formulations is not optimal because it does not precisely match the blend emitted by female moths. The studies reported here were conducted over a 4 -yr period in Wayne, Orleans, and Niagara counties in western New York to address the relationship between moth catch and larval damage in pheromone-treated orchards.

\section{Materials and Methods}

1989. The efficacy of different pheromone dispensers in disrupting mating of $C$. rosaceana males was evaluated in 5 commercial orchards in Wayne County (Table 1). All orchard blocks were established plantings of semidwarf or standard-size trees bordered by other apple plantings or mixed deciduous woodland: Church North ('Rhode Island Greening'), Church South ('Jersey Mac'), Richardson ('McIntosh' and 'Cortland'), Shepherd (McIntosh and 'Golden Delicious'), and Sodus ('Ida Red'). Pheromones were released from dispenser products of 2 types: a $20 \mathrm{~cm}$ polyethylene tube (hereafter designated as a "tie") sealed at both ends and incorporating a wire allowing it to be 
Table 2. Insecticide treatments applied in obliquebanded leafroller pheromone trials, 1989-1991

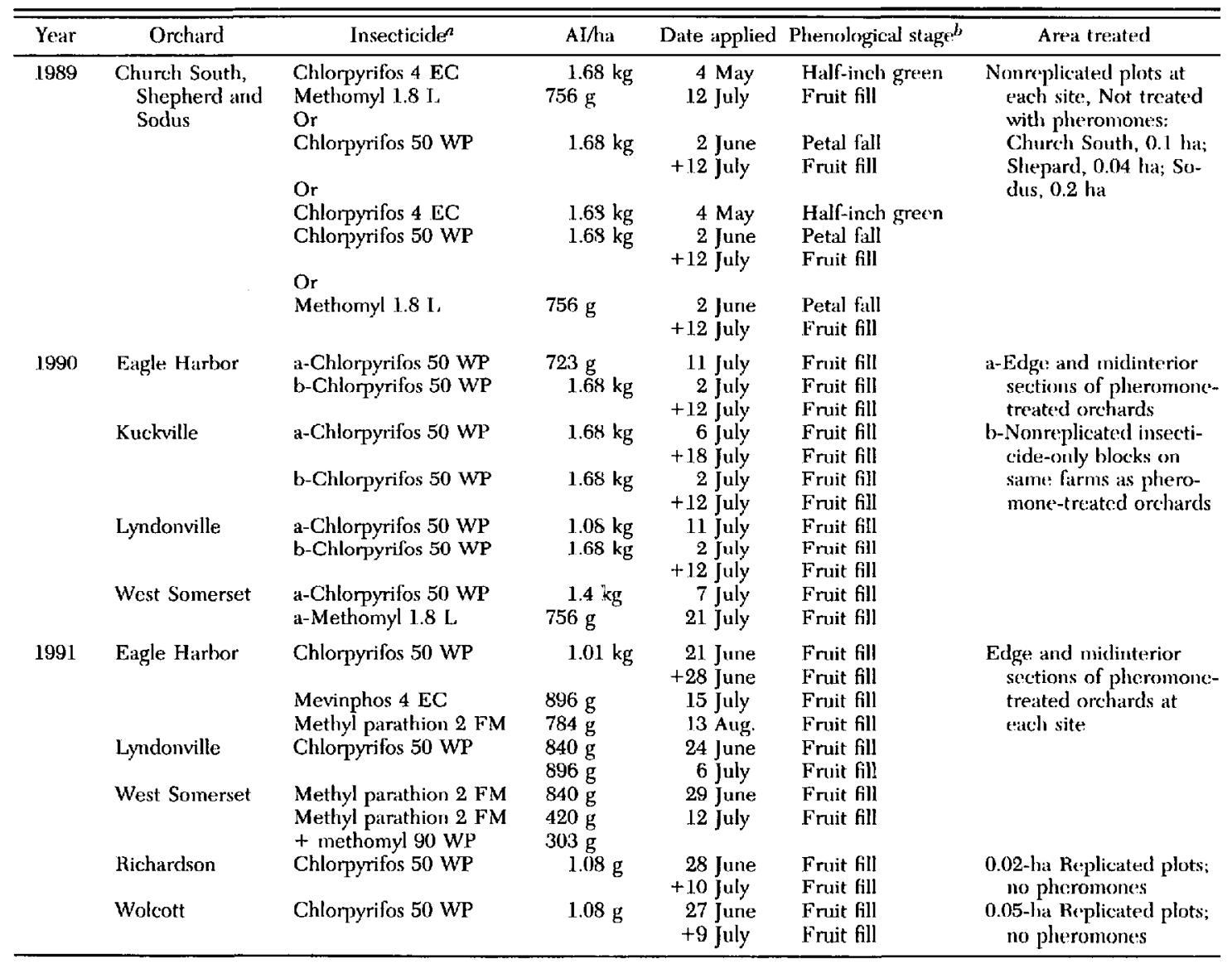

a Chlorpyrifos $4 \mathrm{EC}$ and $50 \mathrm{WP}$ (DowElanco, Indianapolis, IN); methomyl $1.8 \mathrm{~L}$ and 90 WP (Dupont, Wilmington, DE); methyl parathion 2 flowable microcncapsulated ([FM], Elf Atochem, Philadelphia, PA); mevinphos 4 EC (DuPunt).

${ }^{b}$ Half-inch green, $\approx 1 / 2$ inch $(1 \mathrm{~cm})$ of leaf tissue projecting from fruit buds; petal fall, after $\approx 75 \%$ of the petals have fallen; fruit fill, summer period of fruit growth and development.

twisted around a branch (Pacific Biocontrol, Vancouver, WA); and a prototype controlled-release membrane (hereafter designated as a "membrane") with an adhesive backing or a loop closure allowing it to be wrapped around a branch (Consep, Bend, OR). The tie dispensers contained 80.2 $\mathrm{mg}$ (AI) of either the obliquebanded leafroller natural pheromone blend (90:5:5\% Z:E11-14:OAc: Z11-14:OH) or a purported generic leafroller blend (93:5:2\% Z:E11-14:OAc: inert carrier); the membrane dispensers contained $100 \mathrm{mg}$ (AI) of the natural blend. The tie dispensers had a release rate of $\approx 0.025 \mathrm{mg} / \mathrm{h}$ and the membrane dispensers had a release rate of $\approx 0.020-0.027 \mathrm{mg} / \mathrm{h}$, according to information supplied by the respective manufacturers. Each test orchard was subdivided into several adjacent, nonreplicated plots to evaluate various combinations of dispenser types and application rates (Table 1.) All pheromone dispensers were placed in trees at a height of $\approx 1.5 \mathrm{~m}$ above ground level in accordance with manufacturer recommendations, 1 wk before the 1st catch of $C$. rosaceana males in the region, which occurred on
16 June. To monitor orientation disruption of this flight, 3 pheromone traps (Pherocon 1C, Trécé, Salinas, CA) were placed in the interior of each plot on 9 June and checked twice weekly until 27 July. Each trap was baited with a standard rubber septum lure impregnated with the natural pheromone blend components in the amounts $0.485 \mathrm{mg} \mathrm{Z11-}$ 14:OAc, $0.015 \mathrm{mg}$ E11-14:OAc, and $0.025 \mathrm{mg}$ Z1114:OH (Trécé). A group of 3 similar traps also was placed at the edge of each orchard in a plot that was not treated with any insecticides and did not contain pheromone dispensers, to serve as an untreated control, and a single additional trap was placed in another untreated orchard block at least $100 \mathrm{~m}$ from the pheromone plots in the Shepherd, Church South, and Sodus sites, as a remote control.

Additional plots were established at the Shepherd, Church South, and Sodus sites to compare: summer foliar damage in the pheromone treatments with that in trees receiving conventional insecticide spray programs (Table 2). The only earlyseason insecticide in the pheromone plots was 
azimphosmethyl $35 \mathrm{WP}$ ([wettable powder] $838 \mathrm{~g}$ [AI]/ha; Bayer, Kansas City, MO), applied at petal fall for the control of plum curculio, Conotrachelus nemuphar (Herbst). Populations of C. rosaceana in New York have been shown to be resistant to this insecticide and were therefore assumed not to be affected by these applications (Reissig et al. 1986). Foliar terminals and fruit clusters (50 per tree, 10 trees per plot) were sampled to assess the number of sites infested with live summer-generation larvate (14-18 July).

1990. Natural pheromone blend ties similar to those used the previous year were tested in single, nonreplicated plots in commercial orchards in Orleans and Niagara counties, to disrupt mating of both flights of obliquebanded leafroller male moths (Table 1). Pheromone dispensers were distributed from 1-8 June, before the 1st regional catch of male moths, which occurred on 6 June, in all but the Eagle Harbor orchard, where the ties were placed on 8 June. The effectiveness of the pheromone treatments was evaluated by hanging 3 pheromone traps in each test orchard and three traps in a control orchard $\approx 200 \mathrm{~m}$ away at each site. All pheromone traps were similar to those used the previous year. Traps were hung on 30 May and checked twice weekly until 21 September. Plastic bucket traps (1 liter) covered with hardware cloth $\left(0.6-\mathrm{cm}^{2}\right.$ mesh) and baited with $300 \mathrm{ml}$ of a molasses and granulated baker's yeast bait $(1: 10$, molasses to water plus $1.1 \mathrm{~g}$ of yeast per liter of solution) were used to monitor populations of both sexes in the pheromone-treated orchard blocks. On 28 June, 3 of these traps were hung in each test orchard on scaffold branches at a height of $\approx 1 \mathrm{~m}$ above ground level; traps were checked twice weekly until 19 September. Moths collected from the bait traps were placed in $70 \%$ ethanol and dissected in the laboratory to determine their sex and mating status, by the presence of a spermatophore in their bursa copulatrix. Single pheromone traps were hung in each treated block at the orchard edge, in the midinterior region, and near the orchard center, to track moth dispersion patterns within the orchard. Bait traps were hung in a similar pattern using 3 different trees.

To simulate the effectiveness of using pheromone dispensers over an area large enough to minimize infestations by immigrating mated females, a matrix of trees $(4 \times 4)$ in the center of each test orchard received no insecticide applications against 1st summer-generation leafroller larvae. The growers applied their conventional spray program to the remainder of each orchard using chlorpyrifos $50 \mathrm{WP}$ and methomyl $1.8 \mathrm{~L}$ (liquid) (Table 2). As a control, a group of 6-12 trees not treated with insecticides was established $\approx 200 \mathrm{~m}$ from the test blocks at the Eagle Harbor and Kuckville sites, and in a nearby planting on a farm separate from the Lyndonville site. The number of foliar terminals or fruit clusters infested with live larvae was recorded from 50 sites per tree, 4-8 trees per or- chard section at each site (9-12 July). The 3 orchard sections sampled were orchard edge, midinterior (halfway between the orchard edge and the center) and the unsprayed orchard center. By the date of inspection, the growers at 2 of the 4 trial sites had applied insecticide sprays in the orchard edge and midinterior sections of the pheromonetreated blocks, so these plots reflected the effects of both pheromone and insecticide treatments. As a comparison against the effectiveness of insecticides alone, samples also were taken from nonpheromone blocks at each site except for West Somerset in which chlorpyrifos 50 WP had been applied as in a conventional management program (Table 2).

Fruits were evaluated for leafroller damage just before the respective harvest dates for each of the varieties graded in the test blocks. Feeding injury was recorded in 250 apples from each of the 4 innermost unsprayed trees and from 4 trees that had received chemical control sprays in another portion of each pheromone-treated orchard. In addition, 200-500 apples were inspected from each of $5-8$ trees in the blocks that had received only insecticide treatments.

1991. The natural pheromone blend ties similar to those used the previous $2 \mathrm{yr}$ and the membrane dispensers similar to those used in 1989 were evaluated in the same Eagle Harbor, Lyndonville, and West Somerset orchards as in 1990, and in a commercial planting, North Rose, of 'Wayne' apples in Wayne County (Table 1.). All pheromone dispensers were distributed from 29 May to 5 June; the Ist regional catch of male moths occurred on 28 May, Male moths were caught in 3 pheromone traps arranged in each test orchard in a series progressing from the periphery to the orchard center, the same as in 1990 , and in 3 traps in a nonpheromone orchard $\approx 200 \mathrm{~m}$ away at each site. All pheromone traps were similar to those used the previous $2 \mathrm{yr}$. Molasses bait traps were used as in the previous year to monitor populations of both sexes in the disrupted orchard blocks. A total of 24 bait traps per block was arranged in 3 concentric rings of 12,8 , and 4 traps, proceeding from the perimeter to the orchard center, to track moth dispersion patterns within the planting. Moths collected were brought to the laboratory and dissected to determine their sex and mating status. All pheromone and bait traps were set out on 22 May and checked twice weekly until 27 August.

A matrix of trees $(4 \times 4)$ in the center of each test orchard received no insecticide applications against first summer-generation leafroller larvae, similar to the previous year. In the Eagle Harbor, Lyndonville, and West Sornerset orchards, the growers applied their conventional spray program to the remainder of each orchard (Table 2). Foliar terminals and fruit clusters were inspected for infestation by obliquebanded leafroller larvae among treatments from 26 June to 3 July. Terminals or 
clusters infested with live larvae were recorded from 50 to 100 sites per tree, 5-8 trees per orchard section (orchard edge, midinterior and the unsprayed orchard center) at each site. To compare these infestations with those in a conventionally managed orchard, samples were also evaluated in 2 separate commercial orchards located in the same general area of the county as the North Rose site, Richardson, and Wolcott, in which applications of chlorpyrifos $50 \mathrm{WP}$ had been made for leafroller control (Table 2). As a control, samples were taken from trees that had not yet received leafroller insecticide sprays in the nompheromone blocks containing the control pheromone traps. Fruits were evaluated for leafroller damage just before the respective harvest dates for each of the varieties graded in the test blocks. Late-season feeding injury was recorded for 100-180 apple: samples from each of the 4 innermost unsprayed trees and from 4 trees that had received only chemical control sprays at each site.

1992. Laboratory studies were used to determine whether the pheromone blend used in disruptant formulations is optimal. Gas chromatographic analyses of female pheromone gland extracts from both wild and laboratory strains were conducted to determine whether the sex pheromone components and their ratios are in accord with mixtures released from the dispensers. The laboratory colony, which was reared in a greenhouse on fava bean plants (Glass and Hervey 1962), originated from larvae collected in several Wayne County orchards, and had been in culture for $\approx 17$ generations. Last instars from wild, overwintered generation females were collected in Wayne County during late May, and completed their development in the laboratory. After pupation, both laboratory and wild insects were transferred to environmental chambers and maintained at $24^{\circ} \mathrm{C}$ under a photoperiod of 16:8 (L:D) h and 40\% RH. Pheromone glands were excised during midscotophase and extracted in $\mathrm{CS}_{2}$. Each extract contained 4-9 pooled female glands. Samples were concentrated under a gentle stream of $\mathrm{N}_{2}$. Commercially formulated synthetic pheromone dispensers used were the controlled-release membrane in a plastic band (Consep), the same as in the previous field trials. Airborne volatile collections were performed to verify that the membranes were emitting the pheromone components in the proper ratio. A fresh dispenser was suspended in a collection device as described by Baker et al. (1981). Purified nitrogen passed over the dispenser and volatiles were captured on a glass wool plug. The entrained pheromone was rinsed from the glass wool with $\mathrm{CS}_{2}$ and component ratios were quantified by gas liquid chromatography.

To determine the extent of pheromone permeation in the field, a series of pheromone traps was set out in each of 2 pheromone-treated plots at the same Eagle Harbor, Kuckville, and West Somerset sites used the previous 2 yr (Table 1). Pheromones were released from membrane dispensers placed from 28 May to 4 June in the canopies of trees using 1 of the following 2 methods: 1, appropriate: number of dispensers per tree to attain the desired per-hectare rate (494 or 988), all located at a height of 1.5-2 $\mathrm{m}$ above ground level, midway between the top of the canopy and the lowest scaffold branches; 2 , appropriate number of dispensers per tree, with half of the dispensers located in the top of the canopy ( $3-3.7 \mathrm{~m}$ above ground level), and half in the bottom scaffold branches (0.9-1.2 $\mathrm{m}$ above ground level). At both the Eagle Harbor and Kuckville sites, 2 pairs of plots were set up in 2 separate blocks to test the high/low versus midcanopy pheromone placement at the 494 and 988 / ha rates, and a single pair of plots was established at the West Somerset site to test the 988/ha rate.

A 2-tier trap unit was used to measure pheromone ability to disrupt male flight orientation in the highest and lowest canopy regions of the orchard for each of these dispenser arrangements. Each unit consisted of a 3-m pole made of metal conduit tubing ( $1.3 \mathrm{~cm}$ diameter), driven into the ground to reach a height of $\approx 2.7 \mathrm{~m}$ in the canopy at each orchard site. A Pherocon $1 \mathrm{C}$ wing type pheromone trap similar to those used the previous $3 \mathrm{yr}$ was positioned at the top of the pole, and another at the height of the lowest scaffold branches $(0.9-1.2 \mathrm{~m})$. A total of 5 trap units was placed in each pheromone-permeated plot, one in the center and one 3 rows by 3 trees inside of each corner of the plot; each trap was baited with a standard rubber septum lure as in the previous 3 yr. All traps were checked twice weekly from 5 June to 31 July, the duration of the 1st flight.

Pheromone trap catches were subjected to a $\log _{10}(x+1)$ transformation, and all fruit and foliar damage percentages and bait trap catch percentages were transformed using arcsine square root. Analysis of variance (ANOVA) and a least significant difference test (PROC ANOVA, SAS Institute 1985) were used to separate treatment means, with a comparisonwise error rate of $<0.05$.

\section{Results}

1989. Both the tie and membrane pheromone dispensers significantly depressed pheromone trap catches of obliquebanded leafroller in comparison with catches in the nonpheromone control plots (Table 3; Fig. 1). Across sites, the mean number of moths per trap caught during the lst flight was statistically comparable among all pheromone treatments except for the generic blend ties at the lowest rate (494/ha), which achieved only a $55.9 \%$ trap reduction as opposed to an $81.3-97.0 \%$ trap reduction in the former cases. At the Shepherd site, where the membrane and generic blend tie dispensers were used, the lowest catches were obtained in plots treated with the membranes and the ties at the highest rate $(1,976 / \mathrm{ha})$. At the Richardson site, where only generic blend ties were 
Table 3. Mean \pm SEM obliquebanded leafroller moths caught per pheromone trap during Ist $(1989)$ or both $(1990,1991)$ summer flight periods in pheromone-treated orchards, western New York, 1989-1991

\begin{tabular}{|c|c|c|}
\hline Treatment & $n^{a}$ & Moths per trap ${ }^{b}$ \\
\hline \multicolumn{3}{|c|}{1989} \\
\hline Natural blend, tie, $988 /$ ha & 36 & $0.13 \pm$ \\
\hline Natural blend, membrane, $988 /$ ha & 108 & $0.16 \pm 0.57 a$ \\
\hline Generic blend, tie, $1,976 /$ ha & 108 & $0.44 \pm 1.16 \mathrm{a}$ \\
\hline Generic blend, tie, $988 / \mathrm{ha}$ & 108 & $0.80 \pm 2.41 \mathrm{ab}$ \\
\hline Generic blend, tie, $494 / 1$ a & 72 & $1.89 \pm 5.57 \mathrm{~b}$ \\
\hline Control & 180 & $4.28 \pm 8.04 c$ \\
\hline Re:mote control & 36 & $11.81 \pm 20.78 \mathrm{~d}$ \\
\hline \multicolumn{3}{|c|}{1990} \\
\hline Natural blend, tie, 988/ha & 372 & $0.44 \pm$ \\
\hline Control & 372 & $4.18 \pm$ \\
\hline \multicolumn{3}{|c|}{1991} \\
\hline Natural blend, tie, 988/ha & 156 & $0.68 \pm 1.75 \mathrm{a}$ \\
\hline Natural blend, membrane, $988 / \mathrm{ha}$ & 1.53 & $0.94 \pm$ \\
\hline Control & 306 & $3.27 \pm$ \\
\hline
\end{tabular}

a Number of trap-reading observations.

$b$ Within the same year, numbers followed by the same letter are not significantly different (1989: $F=14.17$; $\mathrm{df}=12,635$. 1990: $F=56.93$; df $=6,737$. 1991: $F=28.09$; df $=6,608 ; P>$ $0 .\left(001\right.$, LSD test). Data transformed by $\log _{10}(x+1)$ before analysis.

tested, the lowest rate resulted in higher trap catches than did the 2 higher rates. The natural blend ties were compared against the 2 higher rates of generic blend ties at the Church North site, but population pressure there was so light that virtually no moths were caught in any of the plots except for the remote control. At Church South and Sodus, the membrane dispenser almost completely depressed trap catches compared with those obtained in the control plots.

Foliar terminal infestations on 14 July were significantly lower in all the treatments than in the control plots, and the insecticide treatments were generally more effective than the pheromones in preventing these infestations (Table 4). The plots receiving applications of chlorpyrifos had the lowest overall infestation rates, with no difference between 2 and 3 applications. There were no significant differences in terminal infestation among the different pheromone treatments, and only the natural blend ties and the lowest rate of the generic blend ties were statistically comparable with any of the chemical treatments. It is not known why the higher rates of tie dispensers were not more effective, but these latter treatments were each tested at 3 sites, whereas the former were tested at only 1 and 2, respectively, so it is possible that greater intersite variability contributed to the observed ranking.

1990. Plots with pheromone dispensers exhibited an $89.5 \%$ reduction in pheromone trap catches, in comparison with catches in the control plots (Table 3; Fig. 2). Except for a 2-wk period at the end of August at the Lyndonville site, the ties successfully decreased pheromone catches to negligible levels in all traps within the disrupted blocks.
Moreover, it appears that the effective field life of the product indicates sufficient activity of a single application to cover the adult flights of both generations that occur each year in New York, a period of $90-100 \mathrm{~d}$

The bait station traps also caught a number of moths (Table 5), but the catch trends in these traps were dissimilar to those in the pheromone traps, with no apparent pattern according to time of the season. Although the traps were present in all orchards throughout the summer, the peak catches varied from early July and late August to early September (West Somerset and Kuckville) to midSeptember (Eagle Harbor), and at Lyndonville the catches were low and sporadic all season. More females than males were caught in all orchard sections, and more of these females were mated than virgins, although these differences were significant only in the orchard center. The mean number of moths per trap caught of a given sex or mating status was not significantly different between the edge, midinterior and center of the orchards ( $\mathrm{df}=$ 5, 6; males, $F=3.88 ; P<0.065$; total females, $F$ $=1.40 ; P<0.344$; mated females, $F=1.91$; $P<$ 0.217 ; virgin females, $F=0.29 ; P<0.9022$, least significant difference [LSD] test). Out of 226 total females caught in the bait traps during the summer, $72.1 \%$ were mated.

Results of the foliar inspection conducted in mid-July were recorded first as the overall percentage of terminals that had been fed on at some point in the season before the evaluation date, irrespective of the presence of live larvae in the feeding site. The percentage of terminals being actively fed on at the time of inspection was also noted (Table 6). This is the standard criterion recommended to evaluate the need for chemical control sprays against this larval generation in commercial orchards (Wilcox et al. 1995). Current treatment threshold guidelines recommend an insecticide spray at the $10 \%$ terminal infestation level in July for processing fruit, and at $3 \%$ for fresh market fruit. There were no statistical differences in the percentage of terminals with feeding damage among the pheromone and insecticide treatments, all of which showed damage as severe as that in the untreated checks except for the midinterior insecticide plots. The percentage of foliar terminals infested with live larvae was significantly lower than in the untreated control only in the pheromone + insecticide orchard edge and insecticide-only plots. Infestation in the plots receiving only insecticide sprays was no different from that in any of the pheromone plots. Preharvest fruit inspection for larval feeding damage showed that only the insecticide treatment was significantly lower than the untreated control, but the insecticide-only plots and those receiving both pheromones and insecticide sprays were not significantly different (Table 6).

1991. As in the previous $2 \mathrm{yr}$, the natural blend ties and membrane dispensers significantly de- 

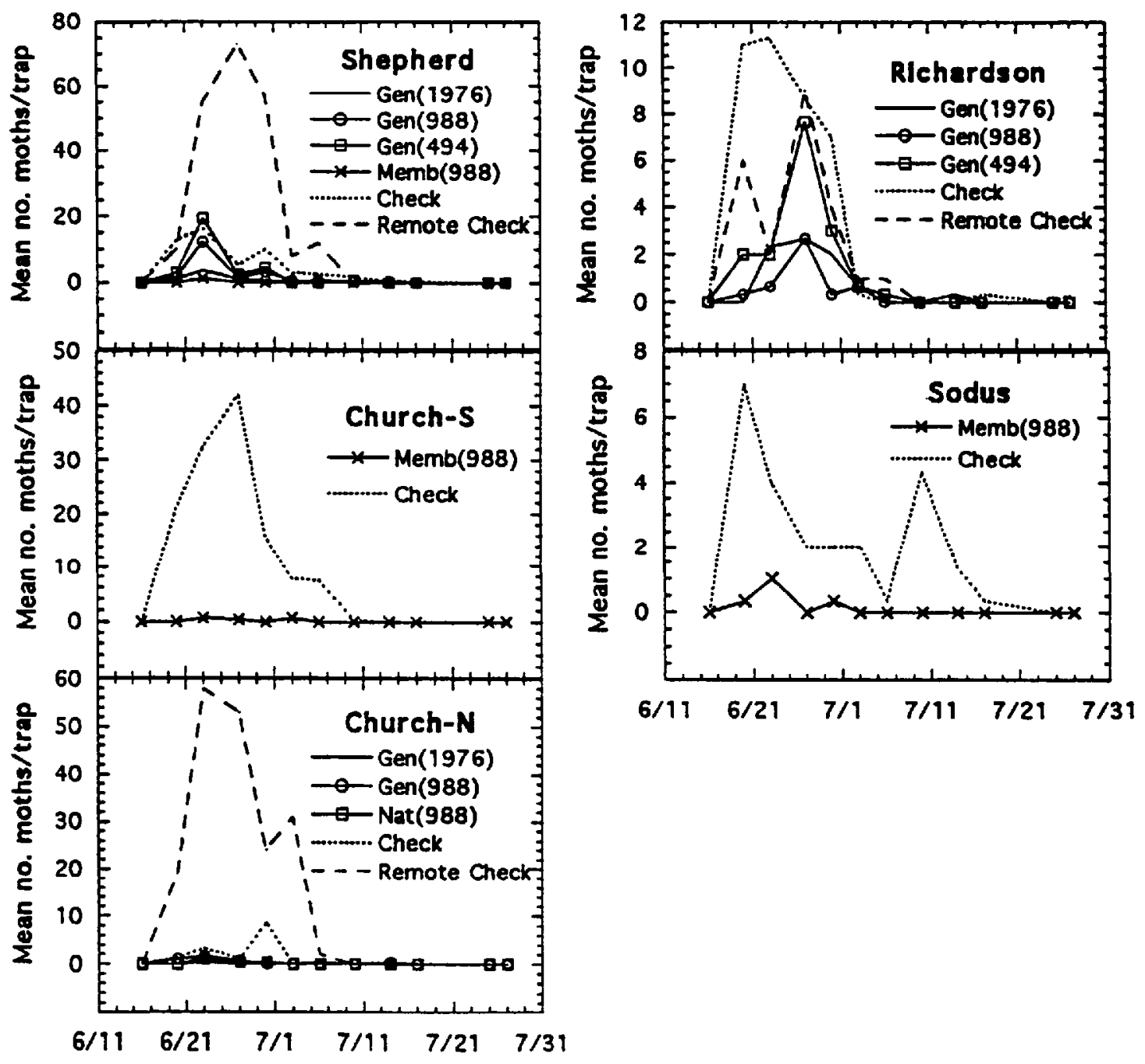

Fig. 1. Captures of $C$. rosaceana male moths in pheromone-baited traps in apple orchards with different pheromone treatments (dispensers per hectare), Wayne County, 1989. Gen, generic blend tie dispenser; Memb, natural blend membrane dispenser; Nat, natural blend tie dispenser.

pressed moth catch in the pheromone-permeated orchards, averaging a $75.3 \%$ trap reduction across treatments compared with the control traps (Table 3; Fig. 3). The occasional higher counts in the pheromone blocks were a result of large catches in pheromone traps located at the orchard edge, where pheromone permeation presumably would not have been as high. In the molasses bait traps, there were no differences in each orchard section in the percentage of moths caught that were males or females (Table 5). The percentage of female moths that were mated versus unmated was numerically higher throughout the orchard, but significantly different only at the orchard edge. The magnitude of leafroller moths caught varied considerably at the 4 locations, ranging from a mean seasonal catch of 35.5 moths per trap at the Eagle Harbor site to 2.3 moths per trap at the North
Rose site. Similarly to 1990, the percentage of all moths caught of a given sex or mating status was not significantly different between the edge, midinterior and center of the orchards $(\mathrm{df}=5,6$; males, $F=1.54 ; P<0.305$; total females, $F=$ $1.45 ; P<0.328$; mated females, $F=1.07 ; P<$ 0.458; virgin females, $F=4.54 ; P<0.465$, LSD test). The percentage of total females caught (786) that were mated was $70.7 \%$, a value comparable to the previous year's measurement of this statistic.

Assessments of treatment effects on foliar terminal infestation and feeding damage were not conducted until after the growers had made insecticide applications in the edge and midinterior sections of the pheromone orchards, so except for the North Rose site, where no insecticides were applied against this pest, the pheromone-only treatment was confined to the center sections of these 
Table 4. Mean \pm SEM percent apple terminals infested with obliquebanded leafroller larvae in orchards treated with pheromones or insecticides, Wayne County, 1989

\begin{tabular}{|c|c|c|c|c|c|}
\hline & & \multicolumn{2}{|l|}{ Treatment } & $n^{a}$ & $\%$ infested $d^{b}$ \\
\hline \multicolumn{6}{|c|}{ Pheromones } \\
\hline Centerice & tie, 494/ha & & & 20 & $6.5 \pm 5.9 b \mathrm{c}$ \\
\hline Cienerice & tic, $988 / \mathrm{ha}$ & & & 30 & $7.5 \pm 5.1 \mathrm{~cd}$ \\
\hline Generic & tie, 1,976/ha & & & 30 & $5.3 \pm 4.8 \mathrm{c}$ \\
\hline Nitural & tic, $988 / \mathrm{ha}$ & & & 10 & $4.4 \pm 3.5 b c$ \\
\hline Nutural & membrane, 988/ha & & & 4]. & $6.8 \pm 6.7 c$ \\
\hline \multicolumn{6}{|c|}{ Insecticides } \\
\hline & 4 May & 2 June & 12 July & & \\
\hline 1 & Chlorpyrifos $4 \mathrm{EC}$ & - & Methomyl 1.8 L & 36 & $3.3 \pm 4.8 \mathrm{~b}$ \\
\hline 2 & Chlorpyrifos $4 \mathrm{EC}$ & Chlorpyrifos $50 \mathrm{WP}$ & Chlorpyrifos $50 \mathrm{WP}$ & 36 & $0.2 \pm 0.8_{\mathrm{d}}$ \\
\hline 3 & - & Methomyl $1.8 \mathrm{~L}$ & Methomyl $1.8 \mathrm{~L}$ & 36 & $2.9 \pm 3.8 \mathrm{~b}$ \\
\hline 4 & - & Chlorpyrifos 50 WP & Chlorpyrifos $50 \mathrm{WP}$ & 36 & $0.7 \pm 1.3 \mathrm{a}$ \\
\hline Control & - & - & - & 69 & $10.7 \pm 10.1 d$ \\
\hline
\end{tabular}

"Number of terminal-inspection observations.

'Numbers in the same column followed by the same letter are not significantly different $(F=7.24 ; \mathrm{d} f=36,307 ; P>0.0001, \mathrm{LSD}$ te'st). Data transformed by arcsine square root before analysis.

orchards (Table 6). As in 1990, none of the pheromone plots had lower levels of feeding damage or infestation with live larvae than did the untreated controls, and the percentage of damaged sites in these treatments was actually significantly higher than in the control plots. The insecticide-only plots averaged $5.3 \%$ terminal infestation, the same value as that obtained the previous year. This was statistically fewer infested terminals than in the other treatments, including those where insecticides had been used in addition to the pheromones. The disparity between these treatments was most likely a result of conducting the insecticide trials on separate farms that had substantially lower leafroller populations than at the pheromone test sites.

Fruit damage was significantly lower in all pheromone and insecticide plots than in the untreated checks, and the insecticide-only treatments located at the Richardson and Wolcott sites showed the lowest level of damage. In the pheromone-treated blocks, fruit damage in the pheromone-only plots was statistically lower than in plots also receiving insecticide applications, but leafroller damage rates $>5-6 \%$ generally are not considered acceptable for commercial fresh fruit production, so neither treatment was particularly successful in adequately protecting the crop from this pest.
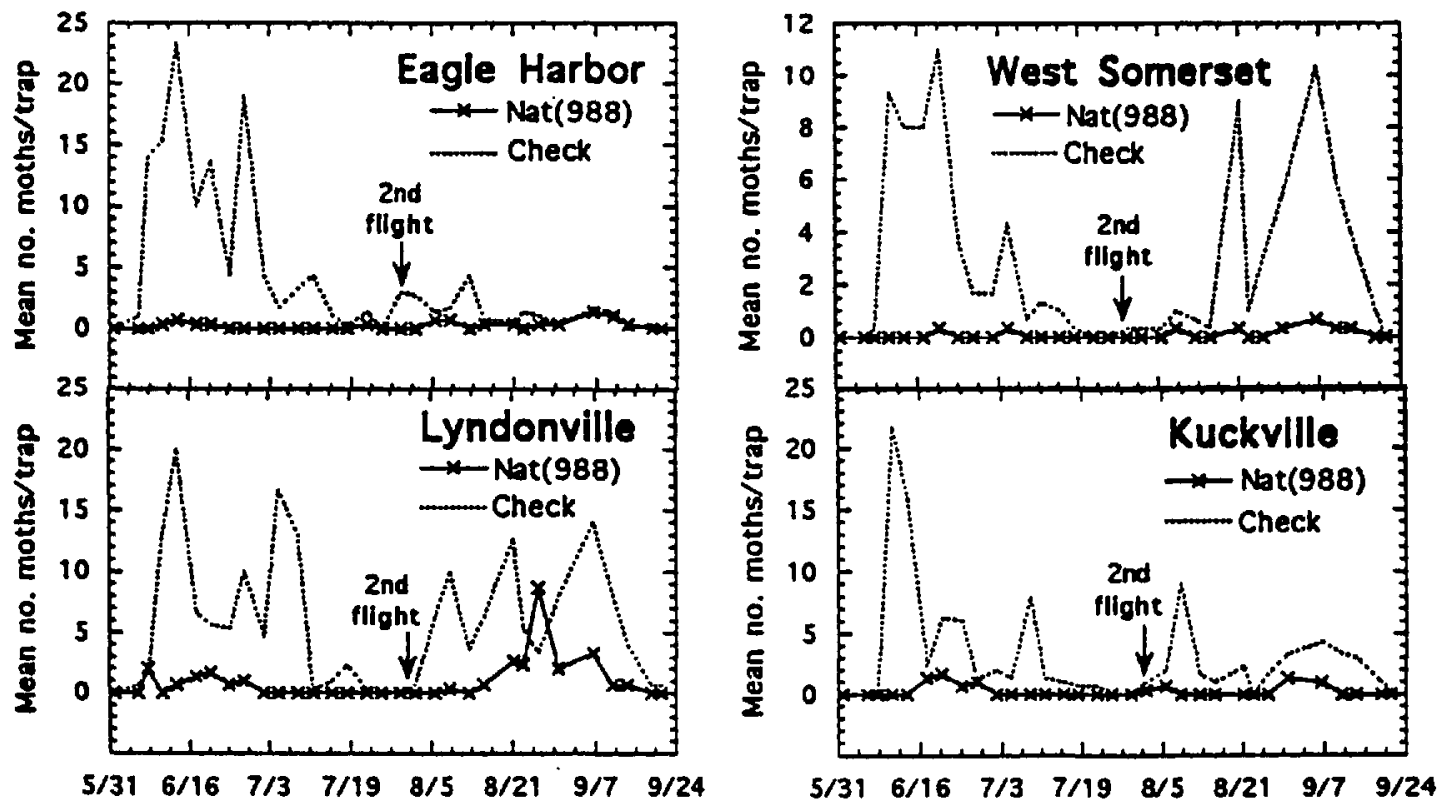

Fig. 2. Captures of $C$. rosaceana male moths in pheromone-baited traps in apple orchards treated with pheromones (dispensers per hectare), Orleans and Niagara counties, 1990. Nat, natural blend tie dispenser. 
Table 5. Sex class of all obliquebanded leafroller moths caught in each section of pheromone-treated orchards using molasses bait traps, Orleans, Niagara, and Wayne counties, July-September 1990 and 1991

\begin{tabular}{|c|c|c|c|c|c|c|}
\hline \multirow{2}{*}{ Sex class } & \multicolumn{6}{|c|}{$\%$ mean $\pm S E M$ of all moths caught in orchard section } \\
\hline & $n^{a}$ & \multirow[t]{2}{*}{ Edge $^{b}$} & $n$ & \multirow[t]{2}{*}{ Midinterior } & $n$ & \multirow[t]{2}{*}{ Center } \\
\hline & & & 1990 & & & \\
\hline Mated females & $53 \pm 13.3$ & $48.9 \pm 20.9 \mathrm{a}$ & $55 \pm 13.8$ & $47.0 \pm 13.3 \mathrm{a}$ & $55 \pm 13.8$ & $58.7 \pm 20.2 \mathrm{a}$ \\
\hline Virgin females & $21 \pm 5.3$ & $22.0 \pm 6.4 a$ & $26 \pm 6.5$ & $20.1 \pm 6.0 \mathrm{a}$ & $16 \pm 4.0$ & $13.8=13.4 b$ \\
\hline Males & $28 \pm 7.0$ & $29.1 \pm 18.5 a$ & $30 \pm 7.5$ & $32.9 \pm 16.2 \mathrm{a}$ & $36 \pm 9.0$ & $27.5 \pm 14.6 \mathrm{ab}$ \\
\hline \multicolumn{7}{|c|}{1991} \\
\hline Mated females & $343 \pm$ & $39.4 \pm 6.1 \mathrm{a}$ & $127 \pm 4.0$ & $24.3 \pm 11.2 \mathrm{~b}$ & $86 \pm$ & $33.4 \pm 23.5 a$ \\
\hline Virgin females & $135 \pm$ & $18.2 \pm 8.4 \mathrm{~b}$ & $69 \pm 2.2$ & $20.8 \pm 12.7 \mathrm{~b}$ & $26 \pm 1.6$ & $15.2 \pm 8.1 a$ \\
\hline Mấes & $357 \pm$ & $42.4 \pm 10.5 \mathrm{a}$ & $207 \geq 6.5$ & $55.1 \pm 8.0 \mathrm{a}$ & $94 \pm 5.9$ & $50.2 \pm 17.9 \mathrm{a}$ \\
\hline
\end{tabular}

a Total moths caught (mean number per trap).

${ }^{b}$ Within the same year, values in each column followed by the same letter are not significantly different (df $=6,9 ; 1990-$ edge: $F$ $=6.20 ; P>0.008$; midinterior: $F=3.54 ; P>0.044$; center: $F=3.74 ; P>0.038 ; 1991$ edge: $F=5.67 ; P>0.011 ;$ midinterior: $F$ $=3.57 ; P>0.043$; center: $F=1.27 ; P>0.359$, LSD test). Data transformed using arcsine square root before: analysis.

1992. Solvent extracts of pheromone glands from laboratory-reared females contained E1.1-14: OAc, Z11-14:OAC, and Z11-14:OH in a proportion of $3.7 \%(0.1, \mathrm{SE}): 91.7 \%(0.2): 4.7 \%(0.4)$. The blend found in wild females differed slightly, in that it contained proportionately less of the alcohol: E11-14:OAc: Z11-14:OAc: Z11-14:OH was 4.3\% (0.2): $93.4 \%(0.4): 2.4 \%(0.2)$. These blends are similar to those found in earlier analyses of OBLR pheromone glands (Hill and Roelofs 1979). The mean proportion of components actually emitted by the membrane dispensers was $89.7 \% \mathrm{Z11}$ 14:OAc, 5.4\% E11-14OAc, and 5.0\% Z11-14:OH $(n=4)$.

Unfavorably cool and wet summer weather resulted in lower pheromone trap catches than those obtained in previous years. Statistically fewer average moths per trap were caught in all plots treated with 988 dispensers per hectare than in those treated with half this rate (Table 7). As in the trials for the previous $3 \mathrm{yr}$, traps hung in the lower canopy locations caught very few moths, especially in contrast to traps in an orchard not treated with pheromones (Fig. 4). However, in every test plot at each site, the pheromone traps placed in the higher canopy locations caught significantly greater numbers of moths than those placed in the lower canopy locations (Figs. 4-6). This effect was generally less pronounced in the plots treated with 988 dispensers per hectare, but the magnitude of the differences was similar to those seen in the plots treated with 494 dispensers per hectare. At this

Table 6. Mean \pm SEM percentage of apple terminals and fruits damaged by obliquebanded leafroller larvace in orehard sections treated with pheromones or insecticides, Orleans and Niagara counties, 1990-1991

\begin{tabular}{|c|c|c|c|c|c|c|}
\hline \multirow{2}{*}{ Orchard section } & \multirow{2}{*}{ Treatment ${ }^{a}$} & \multicolumn{3}{|c|}{ Terminals } & \multicolumn{2}{|r|}{ Fruits } \\
\hline & & $n^{b}$ & $\%$ diamaged sites ${ }^{c, d}$ & $\%$ infested ${ }^{c}$ & $n$ & \% damage ${ }^{c}$ \\
\hline \multicolumn{7}{|l|}{1990} \\
\hline Edge: & Plieromone & 8 & $10.3 \pm 6.9 a b$ & $5.1 \pm 5.0 \mathrm{abc}$ & - & - \\
\hline Edge & Pheromone + insecticide & 8 & $7.1 \pm 3.2 a b$ & $2.3 \pm 2.7 \mathrm{c}$ & - & $\ldots$ \\
\hline Midinterior & Pheromone & 8 & $13.0 \pm 7.3 \mathrm{ab}$ & $9.5 \pm 6.6 \mathrm{ab}$ & - & .... \\
\hline Midinterior & Pheromone + insecticide & 8 & $7.5 \pm 5.3 \mathrm{ab}$ & $4.8 \pm 4.9 \mathrm{abc}$ & 20 & $3.9 \pm 3.2 \mathrm{ah}$ \\
\hline Midinterior & Insecticide & 42 & $8.1 \pm 8.5 \mathrm{a}$ & $5.3 \pm 6.7 b c$ & 21 & $2.1 \pm 2.4 b$ \\
\hline Center & Pheromone & 16 & $9.0 \pm 6.2 \mathrm{ab}$ & $6.3 \pm 5.4 a b c$ & 20 & $4.8 \pm 3.8 \mathrm{a}$ \\
\hline Control & - & 21 & $14.4 \doteqdot 11.6 \mathrm{~b}$ & $10.8 \pm 9.2 \mathrm{a}$ & 42 & $6.7 \pm 8.6 \mathrm{a}$ \\
\hline \multicolumn{7}{|l|}{1991} \\
\hline Edge & Pheromone + insecticide & 16 & $34.2 \pm 18.7 \mathrm{a}$ & $18.1 \pm 6.6 \mathrm{a}$ & - & - \\
\hline Midinterior & Pheromone + insecticide & 16 & $37.0 \pm 23.1 \mathrm{a}$ & $16.6 \pm 10.4 \mathrm{a}$ & 37 & $9.5 \pm 4.7 \mathrm{c}$ \\
\hline Midinterior & Insecticide & 8 & - & $5.3 \pm 6.0 \mathrm{~b}$ & 8 & $3.0 \pm 2.0 \mathrm{a}$ \\
\hline Center & Pheromone & 34 & $22.5 \pm 14.0 \mathrm{~b}$ & $18.6 \pm 14.1 \mathrm{a}$ & 37 & $7.7 \pm 5.1 b$ \\
\hline Control & - & 26 & $17.4 \pm 16.0 \mathrm{c}$ & $19.8 \pm 17.3 \mathrm{a}$ & 8 & $15.5 \pm 10.9 d$ \\
\hline
\end{tabular}

a Pheromone treatments: natural blend ties (1990 and 1991) or membranes (1991), 988/ha; insecticides: chlorpyrifos or microencapsulated methyl parathion, applied Mean $=5.7 \mathrm{~d}$ (range, 2-11) before terminal-sampling date.

${ }^{b}$ Number of terminal- or fruit-inspection observations

c Within the same year, numbers in the same column followed by the same letter are not significantly different (1990: percentage damaged sites, $F=1.65$; df $=24,86 ; P>0.0491$; percentage infested, $F=1.61 ;$ if $=24,86 ; P>0.0579$. 1991: percentage damaged sites, $F=10.21$; $\mathrm{df}=17,89 ; P>0.0001$; percentage infested, $F=3.99 ; \mathrm{df}=17,89 ; P>0.0001$, LSD test). Data transformed by aresine square root before analysis.

"Foliar terminals showing feeding damage, with or without live lar"ate present.

" For the same year, numbers followed by the same letter are not significantly different (1990: $F=2.06$; $\mathrm{df}=22,80 ; P>0.0105$; 1991: $F=6.12 ;$ df $=16,73 ; P>0.0001$. LSD test). 

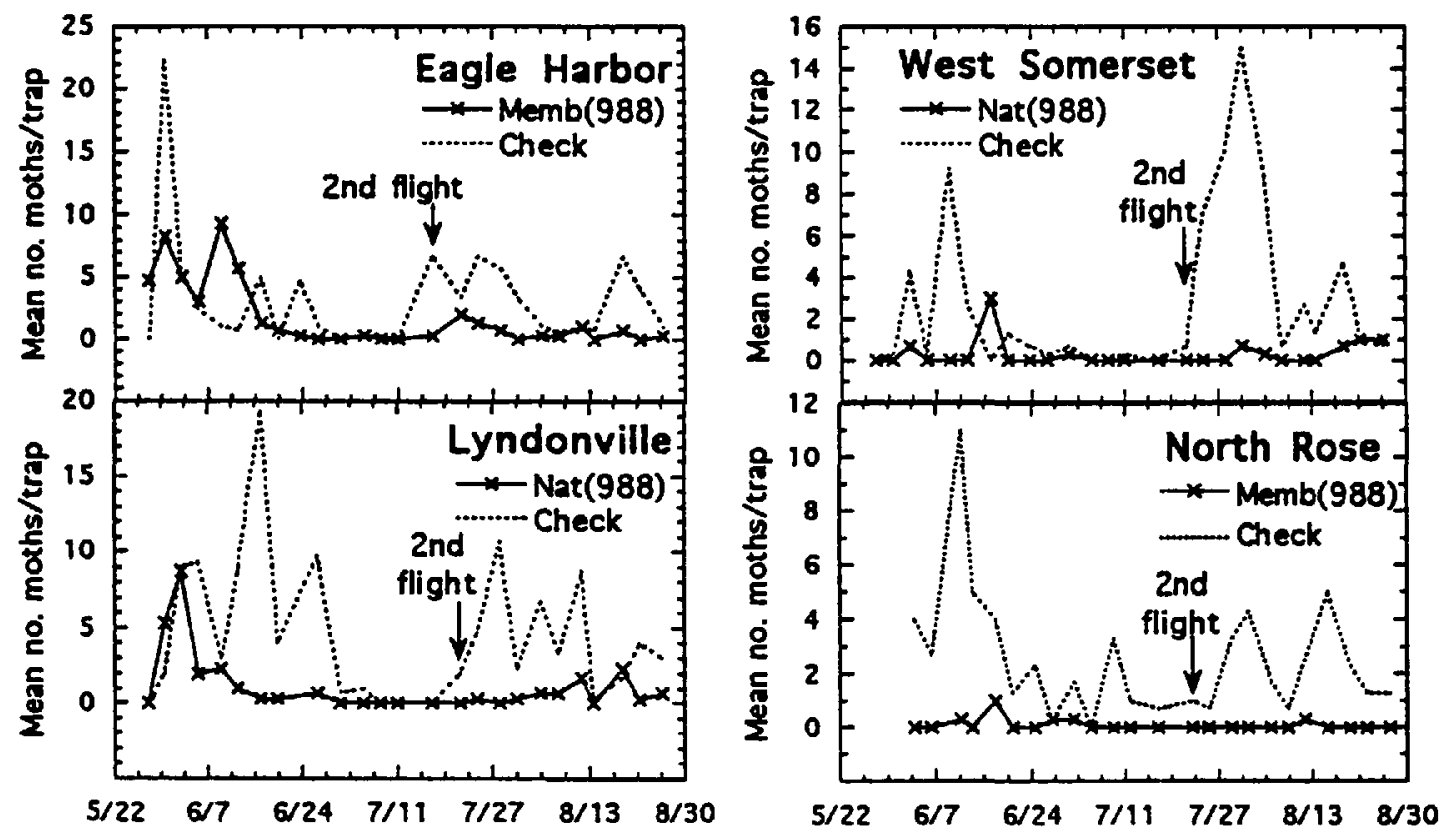

Fig. 3. Captures of $C$. rosaceana male moths in pheromone-baited traps in apple orchards with different pheromone treatments (dispensers per hectare), Wayne, Orleans, and Niagara counties, 1991. Memb, natural blend membrame dispenser; Nat, natural blend tie dispenser.

lower application rate, where less complete pheromone permeation and thus less orientation disruption would be expected, the higher traps often caught moths when the lower traps caught none. A related trend was the frequent occurrence of lower average numbers caught in plots where the pheromone dispensers were placed both high and low in the trees, compared with those in plots where all the dispensers were hung in mid-canopy, although this was not significant across sites.

\section{Discussion}

Reduction in the number of males trapped at synthetic sex pheromone sources can provide some indication of the treatment ability of a pheromone to prevent males from finding virgin females, but this method alone does not demonstrate whether mating is reduced. Rarely is a reduction in mating linked to an equivalent decrease in trapped males, and for many tortricids it is particularly difficult to construct a relationship between males caught and fruit damage because a number of factors have an impact on trap catch, population dynamics, and adult movement and distribution (Rothschild 1981, Charmillot and Vickers 1991.).

Studies in orchards not treated with pheromone disruptants have demonstrated a relationship between pheromone trap location and catch size.

Table 7. Mean \pm SEM obliquebanded leafroller moths caught in pheromone traps placed at different eanopy heights in pheromone-permeated orchurds, western New York, 1992

\begin{tabular}{|c|c|c|c|c|c|c|}
\hline $\begin{array}{l}\text { Dispenser } \\
\text { rate }\end{array}$ & Dispenser location & $n^{b}$ & $\begin{array}{l}\text { Moths per trap, } \\
\text { all traps }\end{array}$ & $\begin{array}{c}\text { Trap } \\
\text { locationd }\end{array}$ & $n$ & Moths per trap' \\
\hline \multirow[t]{2}{*}{$988 / h a$} & \multirow[t]{2}{*}{ Top + bottum of canopy } & \multirow[t]{2}{*}{350} & \multirow[t]{2}{*}{$0.37 \pm 1.08 \mathrm{a}$} & Itigh & 175 & $0.62 \pm 1.40 i \mathrm{t}$ \\
\hline & & & & Low & 175 & $0.12 \pm 0.51 b$ \\
\hline \multirow[t]{2}{*}{ 988/ha } & \multirow[t]{2}{*}{ Midcanopy } & \multirow[t]{2}{*}{350} & \multirow[t]{2}{*}{$0.53 \pm 1.83 a$} & High & 175 & $1.01+2.49 \mathrm{a}$ \\
\hline & & & & Low & 175 & $0.05 \pm 0.26 \mathrm{~b}$ \\
\hline \multirow[t]{2}{*}{$494 / \mathrm{a}$} & \multirow{2}{*}{ Top + bottom of canopy } & \multirow[t]{2}{*}{230} & \multirow[t]{2}{*}{$1.20 \pm 3.02 \mathrm{~b}$} & High & 115 & $2.20 \pm 3.98 \mathrm{a}$ \\
\hline & & & & Low & 1.15 & $0.19 \pm 0.65 \mathrm{~b}$ \\
\hline \multirow[t]{2}{*}{ 494/ha } & \multirow[t]{2}{*}{ Midcanopy } & \multirow[t]{2}{*}{230} & \multirow[t]{2}{*}{$1.34 \pm 3.46 \mathrm{~b}$} & High & .115 & $2.11 \pm 4.01 \mathrm{a}$ \\
\hline & & & & Low & 1.1 .5 & $0.57 \pm 2.60 \mathrm{~b}$ \\
\hline
\end{tabular}

a Natural blend, membranes.

b. Number of trap-reading observations.

- Numbers followed by the same letter are not significantly different ( $F=24.41$; $\mathrm{d} f=10,1,149 ; P>0.0001, \mathrm{LS} \mathrm{D}$ ) tost $)$. Data transformed by $\log _{10}(x+1)$ before analysis.

$d^{\prime}$ High, $2.7 \mathrm{~m}$ above' ground; low, $0.9-1.2 \mathrm{~m}$ above ground.

"For the' same dispenser rate and location, numbers followed by the same letter are not significantly different (988/ha, top + bottom:

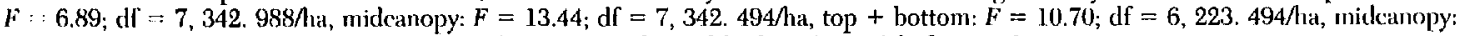
$F=6.46 ; \mathrm{d} f=6,226 ; P>0.0001$, LSD test). Data transformed by $\log _{10}(x+1)$ before analysis. 

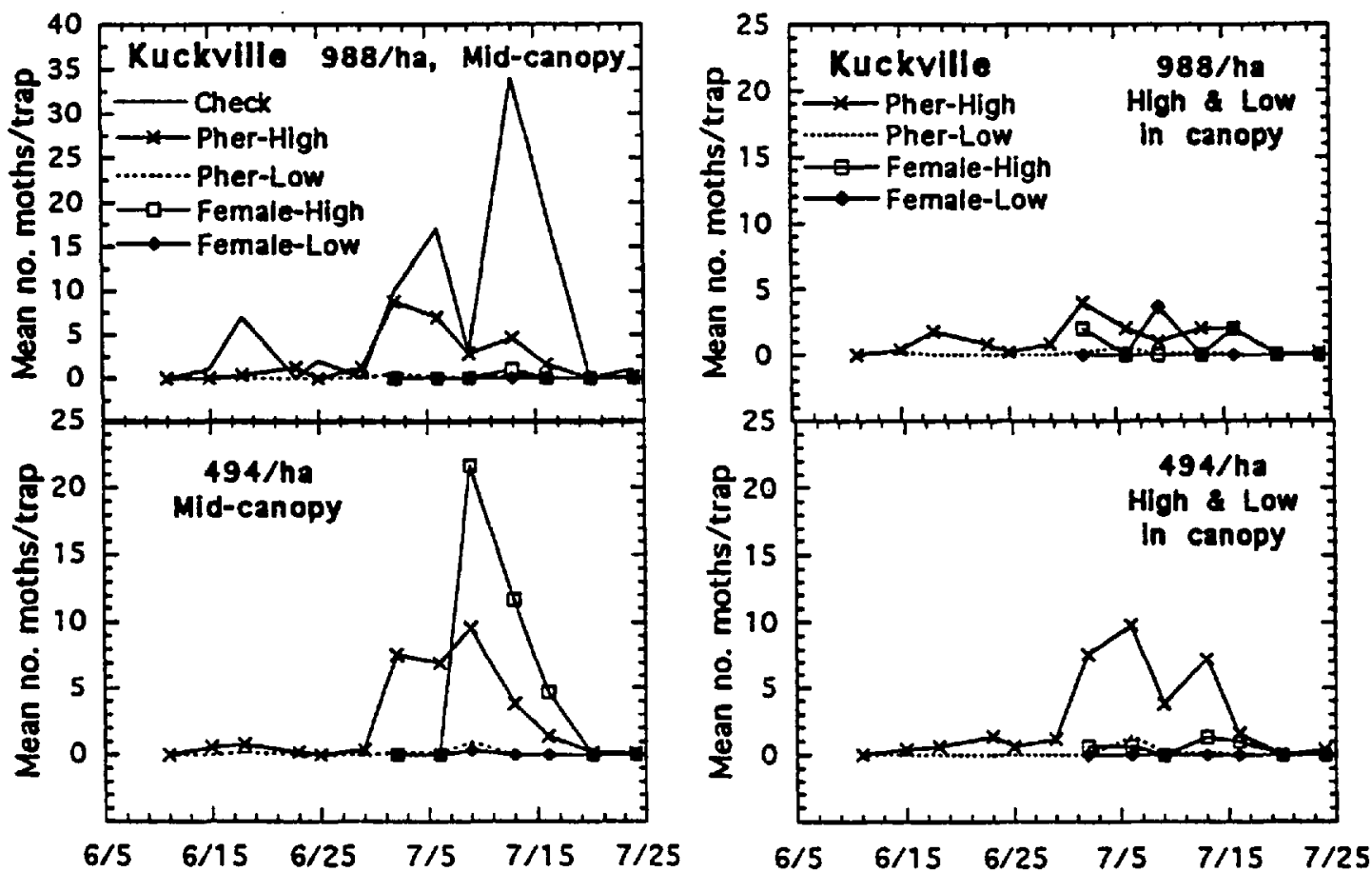

Fig. 4. Captures of $C$. rosaceana male moths in traps placed high or low in tree canopy and baited with rubber septum pheromone lures (Pher) or virgin female moths (Female) in apple orchards treated with different rates of natural blend membrane dispensers, Kuckville, Orleans County, 1.992. Catches from a control orchard not treated with pheromones are shown in the $988 / \mathrm{ha}$, midcanopy graph.
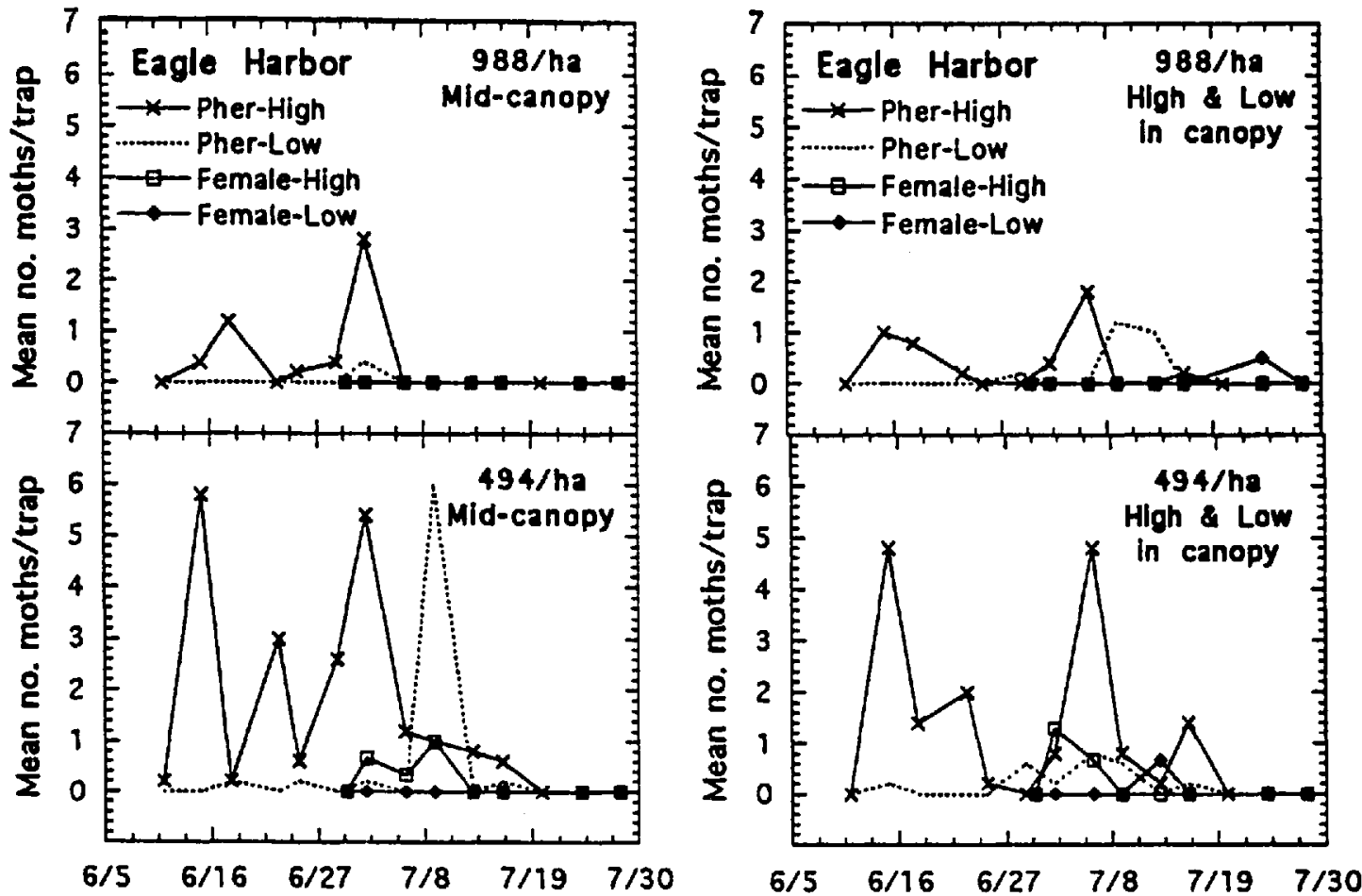

Fig. 5. Captures of C. rosaceana male moths in traps placed high or low in tree canopy and baited witl rubber septum pheromone lures (Pher) or virgin female moths (Female) in apple orchards treated with different rates of natural blend membrane dispensers, Eagle Harbor, Orleans County, 1992. 


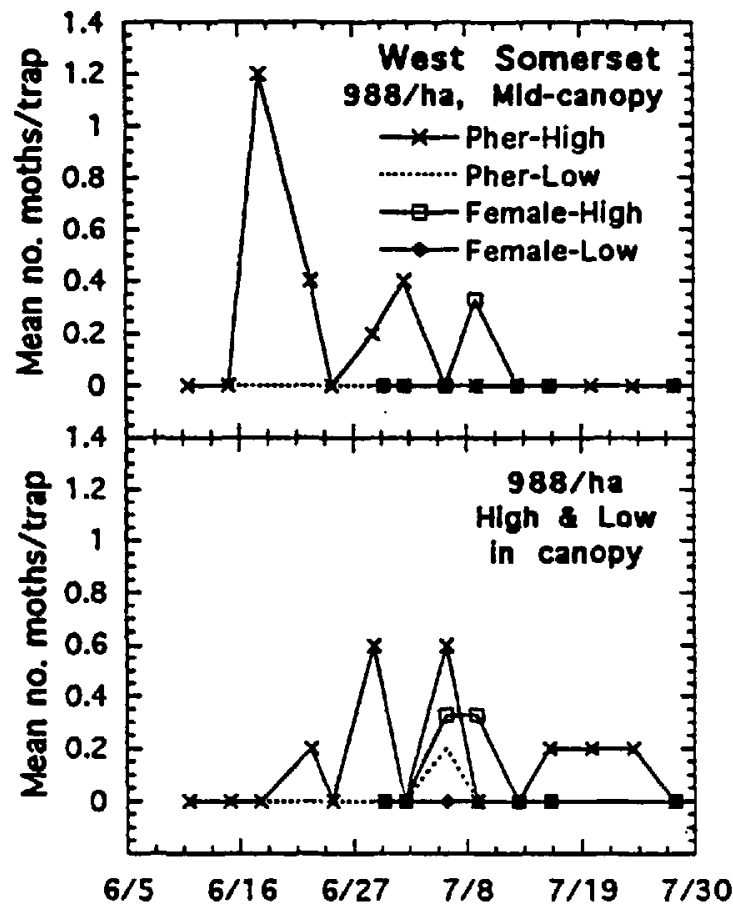

Fig. 6. Captures of $C$. rosaceana male moths in traps placed high or low in tree canopy and baited with rubber. septum pheromone lures (Pher) or virgin female moths (Female) in apple orchards treated with natural blend membrane dispensers, West Somerset, Niagara County, 1992.

Riedl et al. (1979) found that trap height had the most significant effect on pheromone trap catches of codling moth, Cydia pomonella (L.), in apple and pear orchards, with greater catches as trap elevation increased. Similarly, Howell et al. (1990) found that pheromone traps located $3.5 \mathrm{~m}$ high in sprayed apple trees caught more $C$. pomonella moths than those at $1.5 \mathrm{~m} 60 \%$ of the time, and pheromone traps placed $9 \mathrm{~m}$ above the ground in pecan orchards caught more adult males of hickory shuckworm, C. caryana (Fitch), than those placed $4.6 \mathrm{~m}$ high (McVay et al. 1995). Our results in pheromone-treated orchards correspond with these findings, to the extent that more meaningful trap catch data arguably could have been gathered had our traps been located in the upper 3rd of the canopy during all $4 \mathrm{yr}$ of our trials; however, our insight into the mating behavior of this species was not sufficient to prompt this change until the 1992 season.

Optimal height of the pheromone dispensers is another factor dependent on the details of the sexual activity of target species. Rothschild (1975) concluded there was no significant difference in disruption of Cydia molesta (Busck) [=Grapholita molesta (Busck)] when pheromone was released from the crowns of peach trees at $3.5 \mathrm{~m}$ or lower down at $1.5 \mathrm{~m}$, a factor he attributed to adequate aerial distribution of the pheromone in orchard tree crops. However, more recent work has established a vertical variability in pheromone concentrations found in orchards, based on the finding that higher air layers move more freely (Charmillot and Vickers 1991).

Electroantennagram studies in vineyards treated for mating disruption of Lobesia botrana (Denis \& Schiffermiiller) suggest that pheromone is distributed in treated areas as a dense cloud of relatively high concentration, with well defined boundaries and very few internal variations (Karg and Sauer 1995). These studies also found the highest relative pheromone concentration at the same height as the dispensers, with rapidly declining levels both above and below this region. Such findings would be consistent with our results if $C$. rosaceana is more sexually active near the top of the canopy than lower down.

An interpretation can be made that pheromone permeation, especially in the upper canopy areas, is lower and less uniform in the plots containing midcanopy dispensers. If the blend being emitted is correct, females could be mating because coverage is not complete, and relatively pheromonefree zones exist where males could find and mate with them. Cardé and Minks (1995) postulate that, if a point source dispenser is located in the middle of the tree canopy, and the female moth conventionally calls from foliage at the tree top, her plume will be produced in pheromone-free space. Even with as many as half of the per-hectare rate of dispensers placed in the tops of the trees, a certain amount of dissipation could be expected because of greater air movement in that location, leading to some trap catches in those sites.

Our results suggest that obliquebanded leafroller mate locating behavior takes place in or above the top of the tree canopy, either when normal flight orientation in the lower canopy is dismupted, or under any circumstances regardless of pheromone disruptants that may be present. It is commonly observed that obliquebanded leafroller larval infestations tend to be higher near the tops of trees, but explanations of this fact generally center around poorer spray coverage and greater succulent shoot growth in this portion of the tree. It seems likely that a considerable amount of flight and mating behavior may be occurring in the upper canopy areas. Still unexplored is the extent of moth immigration, and whether it occurs primarily near the tree tops, or if one or both sexes Hy into the orchard nearer to the ground and work their way upward in response to extemal stimuli when attempting to locate mates. A logical extension of our trials would be to locate all the pheromone dispensers in the high canopy locations, to see whether effectively increasing the permeation of the air at this level would have an effect on trap catch, mating status and fruit damage.

Traps baited with food lures occasionally have been used as a way of monitoring adults in orchards, although these have been reported to se- 
lectively attract older mated females (Rothschild 1981, Tomkins et al. 1987, Charmillot and Vickers 1991, Suckling et al. 1994). Molasses bait traps in our studies caught more mated than virgin females. We did not collect bait trap data from nonpheromone blocks, so it is not possible to determine whether this is a normal occurrence for this species. However, our results show that mated females were dispersed relatively uniformly throughout pheromone-treated blocks 1.0-2.4 ha in size, and were present in the center at least as frequently as anywhere else in these orchards. In 1991, considering that the proportion of total traps in the edge to midinterior to center orchard sections was in the ratio of $50: 33.3: 16.7 \%$ at each site, the mean percentage of mated females caught in the different section of these orchards (61.7:22.8:15.5\%) conformed fairly closely to these values, with a slight edge effect. This may indicate either that no portion of the permeated orchards was far enough away from nondisrupted areas to overcome immigration potential of the moths, or that the orchards contained resident females that were not prevented from mating by the pheromone treatments.

Foliar and fruit damage patterns, as measured in these trials, provide an indirect but economically relevant method for assessing the success of mating disruption. If the pheromone dispensers had been effective in preventing mating, and if immigration had been negligible, there would have been no infested trees in these blocks, or at least very few in the centers. This was obviously not the case, as terminal infestation rates in the center were at least as high as those on the edge of the block. Fruit damage levels before harvest in 1991 were not as severe as would have been anticipated from the high July infestation readings (Table 6). Adverse summer weather most likely contributed to this outcome. Above-average temperatures (3.2$36^{\circ} \mathrm{C}$ higher than normal) (U.S. Department of Commerce 1991) in late July resulted in poor leaf quality during August, and informal foliar inspections made during August revealed that many larvae had starved before being able to reach the fruit. These findings were consistent with those of Onstad et al. (1986), who demonstrated lower mortality of larvae developing on younger, more succulent apple leaves than those on older ones, which had lower food quality because of diminished nitrogen and water content.

Results of fruit evaluations indicate that there is not always a good correlation between July terminal infestation levels and harvest damage. In 1990, the Kuckville and West Somerset blocks sustained low and high (1.7 and 9.6\%) fruit damage, respectively, consistent with the July terminal infestations (1.4 and 5.2\%). However, the Lyndonville pheromone block technically had an above-threshold population ( $4.3 \%$ infested terminals) in July, yet at harvest the fruit damage was minimal (1.0\%). Leafroller larval populations were larger in 1991, so virtually all treatment sites had foliar terminal infestations $>3 \%$ action threshold (Table 6), but a $13 \%$ reading at the Lyndonville location translated into only $3.1 \%$ fruit damage at harvest, which is considered economically acceptable by growers with routinely high leafroller damage. Similar findings were reported by Pree et al. (1994), who concluded that the incidence of fruit damage at harvest could not be predicted from the incidence of summer damage to peach twigs by larvae of $G$. molesta, another tortricid.

Except for the Ida Red trees at the West Somerset site, where levels of leafroller-damaged fruit were particularly high (pheromone, 9.6\%; insecticide + pheromone, $3.7 \%$ ), the pheromone-treated trees showed fruit damage comparable with that in the orchard sections where growers had additionally applied insecticides on the individual farms (e.g., Eagle Harbor, 4.7:5.3\% pheromone: insecticide + pheromone; Lyndonville, $1.0: 1.4 \%$; Kuckville, 1.7:0.9\%), although the mean damage levels across farms were statistically different for these two categories (Table 6). In the case of the West Somerset Cortland trees, neither treatment was effective enough to prevent economically unacceptable damage at harvest (pheromone, $6.9 \%$; insecticide + pheromone, 8.1\%). Again in 1991, the fruit damage from trees treated with pheromones at a given site was not lowered appreciably by the addition of pesticide applications. Values for pheromone: insecticide + pheromone treatments at individual sites were Eagle Harbor, 13.3:12.1\%; Lyndonville, 3.1:6.3\%; North Rose, 8.1:12.0\%; West Somerset Cortland, 6.9:9.6\%; and West Somerset Ida Red, 8.1:8.3\% fruit damage. Although no commercial formulation of obliquebanded leafroller sex pheromone is currently available for use as a mating disruptant, the cost effectiveness of such a strategy as opposed to using conventional pesticides would ultimately need to be ascertained by each grower according to the specifics of insecticide application costs and reductions in marketable fruit attributable to leafroller damage in each orchard. Informal studies (W.H.R., unpublished data) have demonstrated that, depending on the potential packout loss in the absence of a treatment (i.e., as determined by the relative severity of leafroller damage in a given year), the costs of a given treatment program, and the costs and returns associated with specific packing categories (e.g., average returns of the different packs used, costs of processing culls), it is occasionally less profitable to apply a leafroller treatment than it is to withhold it and allow negligible damage to occur. Such tends to be the case when leafroller pressure is in the low to moderate range (3-5\% fruit damage in untreated orchards). Additionally, it is difficult to evaluate the benefits of withholding leafroller insecticides that are harmful to mite predators, resulting in improved phytophagous mite control that may offset marginally higher fruit damage from leafrollers. 
Future research should address the effectiveness of pheromone application in areas much larger than those tested previously, with an emphasis on the characteristics of the immigration capabilities of this species. The mating behavior of this pest within the orchard remains largely unexplored, but locating the dispensers near the top of the tree canopy to maximize permeation in this region would provide useful information to compare with current findings. A sprayable pheromone formulation, when such becomes available, should be capible of permeating the tree canopy more uniformly than the hand-applied dispensers used in this study.

\section{Acknowledgments}

We thank C. Bailey, D. Bartleson, J. Dubois, O. Kalir, C. Lamont, J. Misiti, D. Oakes, R. Paddock, W. H. Palmerr, J. Peters, T. Staples, and C. Wagemaker for allowing us to work in their orchards and for supplying field expertise. We also thank T. Harris, K. Davis, D. Dunham, K. Hannacker, P. Hezel, J. Minns, Jr, C. Momberger, N. Rivkin, J. Wagar, T. Wheeler, H. Wilcox, M. Wilcox, and $S$. Young (Cornell University) for their field and laboratory assistance. Appreciation goes also to Consep and Pacific Biocontrol for their cooperation and for providing pheromone dispensers. This work was supported by grants from the New York State Department of Agriculture and Markets, Albany, through the Cornell Integrated Pest Management Program.

\section{References Cited}

Buker, T. C., L. K. Gaston, M. M. Pope, L.P.S. Kuenen, and R. S. Vetter. 1981. A high efficiency collection device for quantifying sex pheromone volatilized from female glands and synthetic sources. J. Chem. Ecol. 7: 961-968.

Cardé, R. T., and A. K. Minks. 1995. Control of moth pests by mating disruption: successes and constraints. Aunu. Rev. Entomol. 40: 559-585.

Charmillot, P. J., and R. A. Vickers. 1991. Use of sex pheromones for control of tortricid pests in pome and stone fnuits, pp. 487-496. In L.P.S. van der Geest and H. H. Evenhuis [eds.], Tortricid pests, their biology, natural enemies and control. World Crop Pests vol. 5. Elsevier, Amsterdam.

Deland, J. P., G.J.R. Judd, and B. D. Roitberg. 1994. Disruption of pheromone communication in three sympatric leafroller (Lepidoptera: Tortricidae) pests of apple in British Columbia. Environ. Entomol. 23: 1084-1090,

Glass, E. H., and G.E.R. Hervey. 1962. Continuous rearing of the red-banded leafroller, Argyrotaenia velutinana. J. Econ. Entomol. 55: 336-340.

Hill, A. S., and W. L. Roelofs. 1979. Sex pheromone components of the obliquebanded leafroller moth, Choristoneura rosaceana. J. Chem. Ecol. 5: 3-11.

Howell, J. F., R. S. Schmidt, D. R. Horton, S.U.K. Khattak, and L. D. White. 1990. Codling moth: male moth activity in response to pheromone lures and pheromone-baited traps at different elevations within and between trees. Environ. Entomol. 19: 573577.
Karg, G., and A. E. Sauer. 1995. Spatial distribution of pheromone in vineyards trealed for mating disruption of the grape vine moth Lobesia botrana measured with electroantennograms. J. Chem. Ecol. 21: 12991314.

Karg, G., D. M. Suckling, and S. J. Bradley. 1994. Absorption and release of pheromone of Epiphyes postvittana (Lepidoptera: Tortricidae) by apple leaves. J. Chem. Ecol. 20: 1825-1841.

McVay, J. R., R. D. Eikenbary, R. D. Morrison, C. A. Kouskolekas, and M. Dennison. 1995. Effects of pheromone trap design and placement on capture of male Cydia caryana (Lepidoptera: Tortricidae: Olethreutinae) in Alabama pecan orchards and the relationship of trap captures to fruit infestation. J. Entomol. Sci. 30: 165-1.75.

Onstad, D. W., W. H. Reissig, and C. A. Shoemaker. 1986. Influence of apple cultivar, tree phenology, and leaf quality on the development and mortality of Choristoneura rosaceana (Lepidoptera: Tortricidae). Can. Entomol. 11.8: 123-132.

Palaniswamy, P., R. J. Ross, W. D. Seabrook, G. C. Lonergan, C. J. Wiesner, S. H. Tun, and P. J. Silk. 1982. Mating suppression of caged spruce budivorm (Lepidoptera: Tortricidae) moths in different pheromone atmospheres and high population densities. J. Econ. Entomol. 75: 989-993.

Pree, D. J., R. M. Trimble, K. J. Whitty, and P. M. Vickers. 1994. Control of oriental fruit motlı by mating disruption using sex pheromone in the Niagara Peninsula, Ontario. Can. Entomol. 126: 1.287-1299.

Pfeiffer, D. G., W. Kaakeh, J. C. Killian, M. W. Lachance, and P. Kirsch. 1993. Mating disnuption to control damage by leafrollers in Virginia apple orchards. Entomol. Exp. Appl. 67: 47-56.

Reissig, W. H. 1978. Biology and control of the obliquebanded leafroller on apples. J. Econ. Entomol. 71: 804-809.

Reissig, W. H., and A. M. Agnello. 1991. Management of the obliquebanded leafroller and the use of summer oil against the European red mite. Annu. Rep. Mich. Hortic. Soc. 121: 128-151.

Reissig, W. H., M. Novak, and W. L. Roelofs. 1978. Orientation disruption of Argyrotaenia velutinana and Choristoneura rosaceana male moths. Environ. Entomol. 7: 631-632.

Reissig, W. H., B. H. Stanley, and H. E. Hebding. 1986. Azinphosmethyl resistance and weight-related response of obliquebanded leafroller (Lepidoptera: Tortricidae) larvae to insecticides. J. Econ. Entomol. 79: 329-33.3.

RiedI, H., S. A. Hoying, W. W. Barnett, and J. E. DeTar. 1979. Relationship of within-tree placement of the pheromone trap to codling moth catches. Environ. Entomol. 8: 765-769.

Roelofs, W. L., and M. Novak. 1981. Small-plot disorientation tests for screening potential mating disruptants, pp. 229-242. In E. R. Mitchell [ed.], Management of insect pests with semiochemicals. Plenum, New York.

Roelofs, W. L., and J. P. Tette. 1970. Sex pheromone of the oblique-banded leaf roller moth. Nature (Lond.) 226: 1172 .

Rothschild, G.H.L. 1975. Control of oriental fruit moth (Cydia molesta (Busck) (Lepidoptera, Tortricidae) with synthetic female pheromone. Bull. Entomol. Res. 65: 473-490. 
1981. Mating disnuption of lepidopterous pests: current status and future prospects, pp. 207-228. In E. R. Mitchell [ed.], Management of insect pests with semiochemicals. Plenum, New York.

SAS Institute. 1985. SAS user's guide: statistics, version 5 ed. SAS Institute, Cary, NC.

Suckling, D. M., J. F. Brunner, G. M. Burnip, and J.T.S. Walker. 1994. Dispersal of Epiphyas postvittana (Walker) and Planotortrix octo Dugdale (Lepidoptera: Tortricidae) at a Canterbury, New Zealand orchard. N.Z. J. Crop Hortic. Sci. 22: 225-234.

Tomkins, A. R., D. R. Penman, and R. B. Chapman. 1987. Use of traps for monitoring adult leafrollers in apple orchards. N.Z. J. Exp. Agric. 15: 91-96.

U.S. Department of Commerce. 1991. Local climatological data, Rochester, N.Y., airport. National Oce- anic and Atmospheric Administration, U.S. Department of Commerce, Asheville, NC

Vickers, R. A., G.H.L. Rothschild, and E. L. Jones. 1985. Control of the oriental fruit moth, Cydia molesta (Busck) (Lepidoptera: Tortricidae), at a district level by mating disruption with synthetic female pheromone. Bull. Entomol. Res. 75: 625-634.

Weires, R. W., W. L. Roelofs, and A. E. Robinson. 1978. Pheromone disruption of leafrollers in the Hudson Valley 1976-1977. Proc. Ann. Meet. N.Y.S. Hortic. Soc. 123: 130-135.

Wilcox, W. F., A. M. Agnello, J. Kovach, and W. C. Stiles. 1995. 1995 Pest management recommendations for commercial tree-fruit production. Comell University Press, Ithaca, NY.

Received for publication 3 July 1995; accepted 13 December 1995. 